\title{
Three nested RCTs of dual or single stakeholder feedback within Delphi surveys during core outcome and information set development
}

\author{
Sara Brookes ${ }^{1 *}$, Rhiannon Macefield ${ }^{1}$, Paula Williamson ${ }^{2}$, Angus McNair ${ }^{1}$, Shelley Potter ${ }^{1}$, Natalie Blencowe ${ }^{1,3}$, \\ Sean Strong ${ }^{1}$, Jane Blazeby ${ }^{1,3}$
}

From 3rd International Clinical Trials Methodology Conference

Glasgow, UK. 16-17 November 2015

\section{Background}

In the development of a core outcome or information set the Delphi technique requires participants to rate the importance of items in sequential questionnaires (rounds). Feedback provided in each subsequent round enables participants to consider views of others. This paper examines the impact of separate stakeholder group feedback.

\section{Methods}

Two rounds of Delphi questionnaires were completed by patients and health professionals during the development of three surgical core sets. Participants rated items 1 (not essential) to 9 (absolutely essential). For round 2, participants were randomized to receive feedback from their stakeholder group only (single) or both stakeholder groups separately (dual). Items to retain following each round were determined by pre-specified criteria.

\section{Results}

Type of feedback did not impact on the proportion of items where a participant changed their rating, nor the magnitude of change. Items retained after round 2 were similar between the feedback groups, but each core set contained discordant items retained by one feedback group and not the other (kappa 0.44 to 0.91 ). Consensus between patients and professionals in items to retain was greater amongst those in the dual group in each core set. Differences and variability in round 2 scores were smaller between stakeholders receiving dual feedback $(\mathrm{P} \leq 0.02$ for all).

University of Bristol, Bristol, UK

Full list of author information is available at the end of the article

\section{Conclusions}

In the development of a core outcome or information set, providing feedback within Delphi questionnaires from each stakeholder group separately may influence the final set and improve consensus. Further work is needed to better understand how participants rate and re-rate items within a Delphi process.

\section{Authors' details}

${ }^{1}$ University of Bristol, Bristol, UK. ${ }^{2}$ University of Liverpool, Liverpool, UK.

${ }^{3}$ University Hospitals Bristol NHS Foundation Trust, Bristol, UK.

Published: 16 November 2015

doi:10.1186/1745-6215-16-S2-P51

Cite this article as: Brookes et al:: Three nested RCTs of dual or single stakeholder feedback within Delphi surveys during core outcome and information set development. Trials 2015 16(Suppl 2):P51.
Submit your next manuscript to BioMed Central and take full advantage of:

- Convenient online submission

- Thorough peer review

- No space constraints or color figure charges

- Immediate publication on acceptance

- Inclusion in PubMed, CAS, Scopus and Google Scholar

- Research which is freely available for redistribution

Submit your manuscript at www.biomedcentral.com/submit
( Biomed Central 